\title{
Keynote: \\ Sorry Engineers, but Sustainability \\ Means Lifestyle Change (And only the psychologists can save us)
}

\author{
Eric M Schaffer PhD CUA CPE \\ CEO of Human Factors International Inc \\ www.humanfactors.com
}

\begin{abstract}
The world is in the process of adjusting to the misfortune of ecological limitations. It's nice to caulk your windows. It's nice to use CFL bulbs. It's nice to use electric cars. BUT THERE ARE TWO BILLION PEOPLE IN THE EMERGING MARKETS THAT WANT TO LIVE THE AMERICAN DREAM TOO. What are you going to tell them?

Even the most forward looking models of advanced engineering are just part of the process of denial and negotiation. In the end we will have to live differently. We will have to use less stuff. OH NO!

But actually, more stuff does not make us happier. So it is really not that bad. I'll prove it with data.

We can predicate what this lifestyle will look like because we know it will have to be sustainable (with a smaller ecological footprint) and because people will still try to be happy. I'll give you a list of changes to expect (and that are mostly happening already). There is no question that there will be these types of changes. But they can be either apocalyptic or 'light and connected'. It is the job of the persuasion engineers to make the new lifestyle aspirational. Persuasion engineers go us into this mess by making mega-consumers. They can also get us out. It they don't, we will enter a dark and frugal age of misery.

Interestingly, to succeed with a changed customer and employee ecosystem companies will have to change radically. The 'Light and Connected' lifestyle requires different banking, and cars, and telecommunication, and schools, and, and and...pretty much everything will need to change. Designing and persuading people to live in the new 'Light and Connected' lifestyle is our job for the next few decades. We best move out of denial and get started.
\end{abstract}

\section{BIOGRAPHY}

Armed with a BA in Psychology, Eric M. Schaffer started his long career as a Human Factors Specialist for C.L Mauro Associates in 1977, and went on to work for AT\&T Long Lines before starting his own company: Human Performance Associates (HPA), in 1981.

Along with his two partners, Eric started to figure out how to make a real business out of usability, and Human Performance Associates (HPA) became a successful and pioneering company. In 1988, HPA was split, and Eric set up Human Factors International $(\mathrm{HFI})$ where he continued to specialize in the institutionalization of usability, methodology, and navigation design.

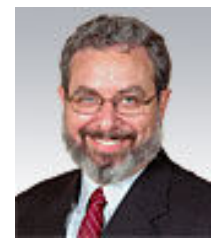

Since its early days in a farm house on the East Coast of the US, Eric has built HFI into a thriving business which now generates over \$16 Million a year and has over 200 staff. But Human Factors International has not been the only focus of Eric's work: He has published several books; acted as consultant for many companies including IBM and MITRE; taught at institutions and companies around the world; and even learned how to fly a plane!

Eric's current projects include the authoring of his latest book: A Sustainable American Dream; How Organizations Can Change the World. 